\title{
Commentary
}

\section{Plastic surgical audit: The need of the hour}

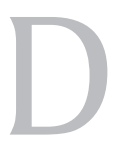

ocumentation of cases, the analysis of data obtained by meticulous documentation, and its regular presentation in the form of an audit, is essential to the progress of any specialty. Trauma cases comprise a large proportion of patients treated in plastic surgical units across the country. The types of trauma referred to plastic surgical units have changed over the years, and injuries that at one time were treated by general surgeons or orthopaedic surgeons, such as scalp lacerations and skin and soft-tissue injuries of the trunk or the extremities, are now being referred to plastic surgeons for treatment, and are being treated well by them. Despite this, plastic surgery does not seem to receive the recognition it deserves from the decision making authorities, be they in public hospitals, corporate private hospitals or in the government hospitals. Plastic surgery is still viewed as a luxury item, deserving of taxation, rather than a necessity in all parts of the country. Even a prestigious government-run institution like the All India Institute of Medical Sciences, New Delhi, does not have a Department of Plastic Surgery. This paper suggests that the situation is no different in our neighbouring countries as well.

Many a limb has been lost, or a facial fracture maltreated, or a face permanently disfigured, for want of a plastic surgeon. The only way to change the perception of plastic

\begin{tabular}{|l|l|}
\multicolumn{3}{c|}{ Access this article online } \\
\hline Quick Response Code: & \\
\hline & Website: \\
\hline
\end{tabular}

surgery, and make people sit up and listen, is to keep records and present departmental audits of plastic surgical cases at regular intervals. Articles such as this are necessary to draw the attention of the authorities to the value of our specialty, and the need to set up more departments and make the specialty more readily available.

Not just in day-to-day trauma, but also in mass casualty situations like terrorist bombings and earthquakes, our specialty has served the country well. In our own small experience, after the $11^{\text {th }}$ July 2007 , Mumbai train blasts, of the 42 patients admitted to a private hospital within few hours of the incidents, 21 were treated primarily by the plastic surgeons. After the 2001 Kutch earthquake, 20 patients with polytrauma were admitted to the hospital for facial, trunk and limb injuries, and 18 of them were treated by the plastic surgeons.

No such audit of plastic surgical trauma has been reported from any unit in our country in the last 10 years. It is high time that all major plastic surgery departments analyzed their cases and presented and published their audits, so that a meaningful data can be collected and used to emphasize the value of our specialty and its role in modern healthcare.

Samir M. Kumta

Sr. Consultant. Departmemt of Plastic Surgery, Lilavati Hospital and Research Centre, Mumbai, India

Address for correspondence: Dr. Samir M. Kumta, 1, Vikas, Vinaya Society, Bhagoji Keer Marg, Mahim, Mumbai - 400 016, India. E-mail: Samir.kumta@gmail.com

How to cite this article: Kumta SM. Plastic surgical audit: The need of the hour. Indian J Plast Surg 2012;45:546.

Source of Support: Nil, Conflict of Interest: None declared. 